\title{
Ticagrelor effectively inhibits platelet aggregation in comatose survivors of cardiac arrest undergoing primary percutaneous coronary intervention treated with mild therapeutic hypothermia
}

\author{
Marek T. Tomala ${ }^{1,2}$ (D) Aleksander Trąbka-Zawickii,2(D, Andrzej Machnik ${ }^{1,2}$, \\ Bartłomiej A. Nawrotek ${ }^{1,2}{ }^{\infty}$, Wojciech Zajdel ${ }^{1,2} \odot$, Ewa Ł. Stępień ${ }^{3} \odot$,

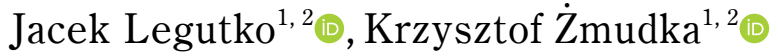

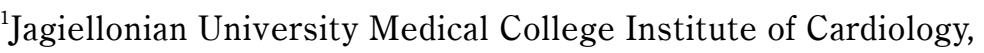 \\ Department of Interventional Cardiology, Krakow, Poland \\ ${ }^{2}$ Krakow Specialist Hospital named after John Paul II, \\ Clinical Department of Interventional Cardiology, Krakow, Poland \\ ${ }^{3}$ Department of Medical Physics, Marian Smoluchowski Institute of Physics, Faculty of Physics, \\ Astronomy and Applied Computer Science, Jagiellonian University, Krakow, Poland
}

\begin{abstract}
Background: Mild therapeutic hypothermia (MTH) is believed to reduce the effectiveness of antiplatelet drugs. Effective dual-antiplatelet therapy after percutaneous coronary intervention (PCI) is mandatory to avoid acute stent thrombosis. The effectiveness of ticagrelor in MTH-treated out-of-hospital cardiac arrest (OHCA) survivors is still a matter of debate. The aim of the study was to evaluate the impact of MTH on the platelet-inhibitory effect of ticagrelor in comatose survivors of OHCA treated with primary PCI.

Methods: Eighteen comatose survivors of $\mathrm{OHCA}$ with acute coronary syndrome undergoing immediate $P C I$ treated with MTH were compared with 14 patients with uncomplicated primary myocardial infarction after PCI, matched for gender and age, in a prospective, single-center, observational study. Platelet aggregation was evaluated using VerifyNow $P_{2} Y_{12}$ point-of-care testing at 3 time points: admission $\left(T_{0}\right)$, during $\operatorname{MTH}\left(T_{1}\right)$, and 48-72 $h$ after rewarming $\left(T_{2}\right)$.

Results: Ticagrelor effectively inhibits platelet aggregation in OHCA patients subjected to MTH and in all patients in the control group. The effectiveness of ticagrelor did not differ between the MTH group and the control group $(p=0.581)$. In 2 cases in the MTH population, the platelet response to ticagrelor was inadequate, and in one of them it remained insufficient during the re-warming phase. There was no stent thrombosis in these patients.

Conclusions: The present study confirmed the effectiveness of ticagrelor to inhibit platelets in myocardial infarction patients after OHCA treated with primary PCI undergoing hypothermia. The use of cooling was not associated with an increased risk of stent thrombosis. (Cardiol J)
\end{abstract}

Key words: out-of-hospital cardiac arrest, platelet function, primary percutaneous coronary intervention, ticagrelor, VerifyNow

Address for correspondence: Marek T. Tomala, MD, PhD, Jagiellonian University Medical College Institute of Cardiology, Department of Interventional Cardiology, Krakow Specialist Hospital named after John Paul II, Clinical Department of Interventional Cardiology, ul. Prądnicka 80, 31-202 Kraków, Poland, tel: +48 501148423, fax: +48 12 6143047, e-mail: marektomala@gmail.com

Received: 16.11.2020 Accepted: 6.06.2021 Early publication date: 16.06.2021

This article is available in open access under Creative Common Attribution-Non-Commercial-No Derivatives 4.0 International (CC BY-NC-ND 4.0) license, allowing to download articles and share them with others as long as they credit the authors and the publisher, but without permission to change them in any way or use them commercially. 


\section{Introduction}

The leading cause of out-of-hospital cardiac arrest (OHCA) is myocardial infarction (MI) $[1,2]$. Patients who survive cardiac arrest (CA) due to acute coronary syndrome should therefore undergo emergency coronary angiography, because $30-40 \%$ of them either have a totally occluded infarctrelated artery or an unstable coronary lesion [2-4]. Aggressive post-CA care, such as coronary artery reperfusion and mild therapeutic hypothermia (MTH), doubles the number of patients that survive to hospital discharge [5]. Effective dual-antiplatelet therapy (DAPT) including acetylsalicylic acid (ASA) and a $\mathrm{P}_{2} \mathrm{Y}_{12}$ receptor inhibitor following a percutaneous coronary intervention (PCI) is mandatory to avoid acute stent thrombosis (ST). Whole-body ischemia caused by CA as a result of reperfusion injury following resuscitation often causes systemic inflammatory response syndrome, which disrupts the coagulation system and platelet function. Moreover, post-resuscitation myocardial dysfunction results in a decreased stroke volume, which, by reducing intestinal blood flow, may lead to an impaired absorption of antiplatelet drugs. MTH $\left(32-34^{\circ} \mathrm{C}\right)$ has become the standard therapeutic option for improving neurological outcomes, and thus survival rates, after OHCA [3]. MTH inhibits the activation of the coagulation system while activating platelet aggregation [6, 7]. Cooling has been shown to augment adenosine diphosphate (ADP)-induced platelet aggregation, resulting in the reduced effectiveness of antiplatelet drugs [8]. Some previous studies have suggested that patients undergoing PCI and MTH after OHCA are at a higher risk of acute ST [9-12]. Other studies, however, including some meta-analyses, indicate that this risk is not actually increased in such patients [13-16]. Therefore, it is particularly important to assess the effectiveness of antiplatelet therapy in patients undergoing MTH after PCI. In this setting, ticagrelor should be the drug of choice before clopidogrel due to its better absorption, faster metabolism, quicker onset of action, and its lack of requirement for metabolic activation [17-21]. The VerifyNow- $\mathrm{P}_{2} \mathrm{Y}_{12}\left(\mathrm{VN}-\mathrm{P}_{2} \mathrm{Y}_{12}\right)$ test we used measures the extent of platelet aggregation in the presence of ticagrelor; its reliability in platelet aggregation assessment in patients with MTH has been previously established [19]. We therefore aimed to test platelet function following administration of ticagrelor in OHCA patients undergoing PCI, who were subjected to MTH for $24 \mathrm{~h}$, and compare the results to a matched patient group with MI without MTH. The aim of the study was to evaluate the impact of MTH on the platelet-inhibiting effect of ticagrelor in comatose survivors of OHCA who underwent primary PCI.

\section{Methods}

We conducted a prospective, single-center observational study. The protocol was approved by the Jagiellonian University Ethics Committee in Krakow. Written informed consent was obtained from patients regaining consciousness after $\mathrm{CA}$ and conscious patients with acute coronary syndrome. Therapeutic hypothermia was achieved by using an endovascular cooling device (Zoll Medical Corporation Chelmsford, MA) to a target temperature of $32.0^{\circ} \mathrm{C}$ maintained for $24 \mathrm{~h}$. Subsequently, rewarming was performed at a rate of $0.2^{\circ} \mathrm{C} / \mathrm{h}$.

The inclusion criteria for this study were patients aged 18 years or older, who had OHCA from an MI with return of spontaneous circulation, who survived $24 \mathrm{~h}$ after admission and were treated with DAPT. The exclusion criteria included known coagulopathy, anticoagulation with a vitamin $\mathrm{K}$ antagonist (international normalized ratio within the therapeutic range), intake of a direct oral anticoagulant, effective inhibition of platelet function on admission, MTH pre-hospital, periprocedural use of glycoprotein IIb/IIIa receptor inhibitor, or those who were already taking clopidogrel, prasugrel, or ticagrelor. Patients were enrolled in the MTH group between January 2014 and January 2016. The control group consisted of gender- and age-matched patients with uncomplicated MI after undergoing a primary PCI and were admitted between December 2015 and August 2017. During MTH, all patients received an IV injection of analgesic opioid and sedation drugs. Neuromuscular blockade was often used according to the protocol of MTH. A loading dose (LD) of $300 \mathrm{mg}$ ASA and $180 \mathrm{mg}$ ticagrelor were administered via a nasogastric tube on admission, followed by $75 \mathrm{mg}$ ASA once daily and $90 \mathrm{mg}$ ticagrelor twice daily. The control group patients were administered ASA and ticagrelor orally according to the same protocol. The mean time between the first maintenance dose of ticagrelor (270 mg) and blood sampling in the MTH group was $495 \pm 219 \mathrm{~min}$. Prior to the procedure, platelet function was assessed using $\mathrm{VN}-\mathrm{P}_{2} \mathrm{Y}_{12}$ point-of-care testing (Accumetrics Ltd., San Diego, CA, USA). A cut-off value below 194 platelet reactivity units (PRU) was adopted as evidence of a $\mathrm{P}_{2} \mathrm{Y}_{12}$ effective platelet function inhibition [22, 23]. Platelet aggregation was evaluated at 3 timepoints: when 
Table 1. Clinical characteristics.

\begin{tabular}{lccc}
\hline Variable & MTH group $(\mathbf{n}=\mathbf{1 8})$ & Control group $(\mathbf{n}=14)$ & $\mathbf{P}$ \\
\hline Males & $14(78 \%)$ & $12(86 \%)$ & 0.909 \\
Age & $68 \pm 10$ & $66 \pm 9$ & 0.742 \\
History of MI & $1(6 \%)$ & $2(14 \%)$ & 0.819 \\
History of revascularization & $2(11 \%)$ & $2(14 \%)$ & 0.788 \\
Arterial hypertension & $13(72 \%)$ & $10(71 \%)$ & 0.729 \\
Diabetes mellitus type & $5(28 \%)$ & $3(21 \%)$ & 1 \\
Obesity & $8(44 \%)$ & $2(14 \%)$ & 0.149 \\
Stroke & $1(6 \%)$ & $0(0 \%)$ & 0.898 \\
Dyslipidemia & $9(50 \%)$ & $6(43 \%)$ & 0.964 \\
Tobacco smoking & $5(28 \%)$ & $2(14 \%)$ & 0.628 \\
Peripheral artery disease & $1(6 \%)$ & $2(14 \%)$ & 0.819 \\
\hline
\end{tabular}

Values are shown as mean \pm standard deviation (SD) or number (percentage); $\mathrm{MI}$ — myocardial infarction; MTH — mild therapeutic hypothermia

baseline blood samples were taken prior to $\mathrm{LD}\left(\mathrm{T}_{0}\right)$, when samples were drawn during MTH 12-24 h after $\mathrm{LD}\left(\mathrm{T}_{1}\right)$, and $48-72 \mathrm{~h}$ after re-warming $\left(\mathrm{T}_{2}\right)$. All patients in the MTH group reached the target temperature $\left(32^{\circ} \mathrm{C}\right)$ during sampling. The average core temperature between groups of patients after $\mathrm{CA}$ and control at the 3 timepoints were $35.3 \pm$ $\pm 0.6^{\circ} \mathrm{C}$ vs. $36.3 \pm 0.5^{\circ} \mathrm{C}$ at $\mathrm{T}_{0}, 32.2 \pm 0.1^{\circ} \mathrm{C}$ vs. $36.7 \pm 0.4^{\circ} \mathrm{C}$ at $\mathrm{T}_{1}$, and $36.7 \pm 0.1^{\circ} \mathrm{C}$ vs. $36.6 \pm 0.4^{\circ} \mathrm{C}$ at $\mathrm{T}_{3}$, respectively. The key outcome variable was the level of effective platelet inhibition after ticagrelor administration, as assessed by $\mathrm{VN}-\mathrm{P}_{2} \mathrm{Y}_{12}$, which was measured at the timepoints specified above. We also monitored the presence of ST [24] and the occurrence of major bleeding as defined by the Bleeding Academic Research Consortium (BARC) for bleeding classification [25]. The VN- $\mathrm{P}_{2} \mathrm{Y}_{12}$ assay we used in our study was a point-of-care test, which is widely used to assess residual platelet reactivity in patients with MTH [26-29].

\section{Statistical analysis}

All statistical analyses were carried out using SAS software (version 4.0, SAS Institute Inc.). Categorical variables were presented as numbers of subjects and percentages. Continuous variables were analyzed for normal distribution using the Shapiro-Wilk test and were presented as mean \pm standard deviation for normal distribution and as median values with lower and upper quartiles for non-normal distribution. Differences for continuous variables between groups (MTH vs. control) were analyzed using a parametric Student's test or Mann-Whitney U-test, as appropriate. Categorical data were compared using the $\chi^{2}$ test or $\chi^{2}$ test with
Yates' correction. $\mathrm{P}$ values less than 0.05 were considered significant

\section{Sample size calculation}

Based on previously published data involving patients with ST-segment elevation MI [30] and our own database [7] and considering values of PRU Mi1 $=46$ and PRU Mi2 = 105 for both groups, respectively, we estimated that at least 17 patients were required to reach statistical significance using a power of $80 \%$ and a 2 -sided $\alpha$-level of 0.05 , $\delta=60$.

\section{Results}

\section{Patient characteristics}

We prospectively included 18 patients who were admitted for an acute MI after OHCA and subsequently underwent primary $\mathrm{PCI}$ and were subjected to MTH for $24 \mathrm{~h}$. They were compared to 14 matched patients who were admitted to the hospital due to MI and were undergoing PCI but were not in CA (control group). There was no difference in demographics, medical history, or periprocedural details between the groups. No patient in the control group was treated with opiates during transport or during hospitalization. The baseline clinical characteristics are shown in Table 1, the characteristics of the MTH group are shown in Table 2, and hospitalization details are depicted in Table 3.

Platelet count in patients in the MTH group decreased significantly after implementing MTH from $194 \pm 52\left[10^{-3} / \mu \mathrm{L}\right]\left(\mathrm{T}_{0}\right)$ to $149 \pm 38\left[10^{-3} /\right.$ $\mu \mathrm{L}]\left(\mathrm{T}_{1}\right)(\mathrm{p}<0.001)$. This phenomenon persisted 
Table 2. Characteristics of mild therapeutic hypothermia (MTH) group $(\mathrm{n}=18)$.

\begin{tabular}{lc}
\hline \multicolumn{2}{l}{ Cardiac arrest data } \\
Initial cardiac arrest rhythm: \\
VF/VT & $15(83 \%)$ \\
Asystole & $1(6 \%)$ \\
Pulseless electrical activity & $2(11 \%)$ \\
Time to ROSC [min] & $21 \pm 15$ \\
Witness & $18(100 \%)$ \\
Bystander CPR & $11(61 \%)$ \\
Condition at admission to hospital & \\
GCS score (3-4) & $10(56 \%)$ \\
GCS score (5-6) & $8(44 \%)$ \\
Cardiogenic shock & $3(17 \%)$ \\
Circumstances and details of MTH & \\
Time to MTH [min] & $129 \pm 51$ \\
Total time of MTH [min] & $1480 \pm 149$ \\
Neurological outcome & \\
Good neurological outcome & $12(67 \%)$ \\
at discharge & \\
Death during hospitalization & $1(6 \%)$ \\
\hline
\end{tabular}

Values are shown as mean \pm standard deviation or number (percentage); CPR - cardiopulmonary resuscitation; GCS - Glasgow Coma Scale; ROSC - return of spontaneous circulation;

VT/VF — ventricular tachycardia/ventricular fibrillation after the re-warming phase with a platelet count of $141 \pm 45\left[10^{-3} / \mu \mathrm{L}\right]\left(\mathrm{T}_{2}\right)$, (Table 4$)$.

\section{Antiplatelet results using $\mathrm{VN}-\mathrm{P}_{2} \mathrm{Y}_{12}$}

Platelet reactivity unit values did not differ significantly between the MTH group and the control group in any of the evaluated timepoints. In the MTH population, the average PRU after a LD of ticagrelor fell from $265 \pm 41$ at the baseline $\left(\mathrm{T}_{0}\right)$, to $87 \pm 89$ at $\mathrm{T}_{1}(\mathrm{p}=0.44)$. There was an increase in the percentage of mean platelet inhibition from $0.2 \pm 0.9\left(\mathrm{~T}_{0}\right)$ to $67 \pm 3\left(\mathrm{~T}_{1}\right)(\mathrm{p}=0.856)$ and at $\mathrm{T}_{1}$, 2 out of $18(11 \%)$ patients had inadequate platelet inhibition $(\mathrm{p}=0.851)$. After re-warming, we recorded sustained antiplatelet effect of ticagrelor with a PRU value of $64 \pm 53\left(\mathrm{~T}_{2}\right)$ and mean platelet inhibition percentage of $75 \pm 19\left(\mathrm{~T}_{2}\right)$. All patients except $1(5.5 \%)$ in $\mathrm{T}_{2}$ demonstrated effective inhibition of platelets with ticagrelor (Figs. 1-3). Similar results were observed in the control group (Table 5).

\section{Stent thrombosis and bleeding}

No cases of ST occurred during hospitalization in either group. In the MTH group, 6 (34\%) patients experienced BARC 3a bleeding vs. none in the control group ( $p=0.052$; Table 3$)$. In 2 subjects, the bleeding affected the upper gastro-

Table 3. Hospitalization details.

\begin{tabular}{lccc}
\hline Variable & $\begin{array}{c}\text { MTH group } \\
(\mathbf{n}=18)\end{array}$ & $\begin{array}{c}\text { Control group } \\
\text { (n = 14) }\end{array}$ & P \\
\hline Cardiogenic shock at admission & $3(17 \%)$ & $0(0 \%)$ & 0.321 \\
STEMI & $9(50 \%)$ & $8(57 \%)$ & 0.964 \\
Acute coronary occlusion & $10(56 \%)$ & $9(50 \%)$ & 0.892 \\
MVD (2 or 3) & $9(50 \%)$ & $7(50 \%)$ & 0.722 \\
PCl success & $17(94 \%)$ & $14(100 \%)$ & 0.898 \\
Cardiogenic shock during hospitalization & $8(44 \%)$ & $0(0 \%)$ & 0.014 \\
Stent thrombosis & $0(0 \%)$ & $0(0 \%)$ & - \\
Pneumonia & $12(67 \%)$ & $0(0 \%)$ & 0.001 \\
Bleeding BARC 3a & $3(17 \%)$ & $0(0 \%)$ & 0.321 \\
Bleeding BARC 3b & $3(17 \%)$ & $0(0 \%)$ & 0.321 \\
Major bleeding & $6(33 \%)$ & $0(0 \%)$ & 0.052 \\
Renal failure & $13(72 \%)$ & $1(7 \%)$ & 0.001 \\
GFR & $54 \pm 22$ & $78 \pm 16$ & 0.009 \\
Stroke & $2(11 \%)$ & $0(0 \%)$ & 0.492 \\
\hline
\end{tabular}

Values are shown as mean \pm standard deviation or number (percentage); BARC — Bleeding Academic Research Consortium; GFR - glomerular filtration rate; MTH - mild therapeutic hypothermia; MVD — multi-vessel disease; $\mathrm{PCl}$ — percutaneous coronary intervention; STEMI — ST-segment elevation myocardial infarction 
Table 4. Platelet count.

\begin{tabular}{lccc}
\hline Platelet count $\left[10^{-3} / \mu \mathrm{L}\right]$ & MTH group $(\mathbf{n}=\mathbf{1 8})$ & Control group $(\mathbf{n}=\mathbf{1 4})$ & $\mathbf{P}$ \\
\hline Basal $\left(\mathrm{T}_{0}\right)$ & $194 \pm 52$ & $232 \pm 52$ & 0.166 \\
MTH $\left(\mathrm{T}_{1}\right)$ & $149 \pm 38$ & $223 \pm 50$ & 0.004 \\
NT $\left(\mathrm{T}_{2}\right)$ & $141 \pm 45$ & $208 \pm 38$ & 0.004 \\
\hline
\end{tabular}

Values are shown as mean \pm standard deviation; MTH - mild therapeutic hypothermia; NT — normothermia; $\mathrm{T}_{0}$ - after admission; $\mathrm{T}_{1}$ - $12-24 \mathrm{~h}$ after percutaneous coronary intervention; $\mathrm{T}_{2}-48-72 \mathrm{~h}$ after percutaneous coronary intervention

Table 5. Sample collection and results of VerifyNow- $\mathrm{P}_{2} \mathrm{Y}_{12}$ test in mild therapeutic hypothermia (MTH) group versus control group.

\begin{tabular}{|c|c|c|c|c|c|c|c|c|c|}
\hline \multirow[t]{2}{*}{ Variable } & \multicolumn{3}{|c|}{$\mathbf{T}_{0}$} & \multicolumn{3}{|c|}{$\mathbf{T}_{1}$} & \multicolumn{3}{|c|}{$\mathbf{T}_{2}$} \\
\hline & $\begin{array}{c}\text { MTH } \\
(n=18)\end{array}$ & $\begin{array}{l}\text { Control } \\
(n=14)\end{array}$ & $\mathbf{P}$ & $\begin{array}{c}\text { MTH } \\
(n=18)\end{array}$ & $\begin{array}{l}\text { Control } \\
(n=14)\end{array}$ & $\mathbf{P}$ & $\begin{array}{c}\text { MTH } \\
(n=18)\end{array}$ & $\begin{array}{l}\text { Control } \\
(n=14)\end{array}$ & $\mathbf{P}$ \\
\hline PRU & $265 \pm 41$ & $251 \pm 42$ & 0.44 & $87 \pm 89$ & $31 \pm 38$ & 0.110 & $64 \pm 53$ & $41 \pm 28$ & 0.081 \\
\hline $\begin{array}{l}\text { Percentage of platelet } \\
\text { inhibition }\end{array}$ & $0.2 \pm 0.9$ & $0.4 \pm 1.3$ & 0.856 & $67 \pm 31$ & $86 \pm 16$ & 0.202 & $75 \pm 19$ & $83 \pm 12$ & 0.169 \\
\hline $\begin{array}{l}\text { Number of patients with } \\
\text { satisfactory effect } \\
\text { (PRU < 194) }\end{array}$ & - & - & - & $16(89 \%)$ & $14(100 \%)$ & 0.581 & $17(94 \%)$ & $14(100 \%)$ & 0.898 \\
\hline
\end{tabular}

Values are shown as mean \pm standard deviation; number of patients with given score (\%); PRU — platelet reactivity units; $\mathrm{T}_{0}-$ after admission; $\mathrm{T}_{1}-12-24 \mathrm{~h}$ after percutaneous coronary intervention; $\mathrm{T}_{2}-48-72 \mathrm{~h}$ after percutaneous coronary intervention; PRU $\mathrm{T}_{0}$ statistical power: 0.21 ( $\mathrm{Mi1}=264.9 ; \mathrm{Mi} 2=246.1 ; \delta=44.9 ; \alpha=0.05) ; \mathrm{PRU} \mathrm{T}_{1}$ : statistical power: 0.51 (Mi1 = 86.7; Mi2 = 31.1; $\left.\sigma=75.63 ; \alpha=0.05\right) ; \mathrm{PRU} \mathrm{T}_{3}$ statistical power: 0.27 ( $\mathrm{Mi} 1=63.6 ; \mathrm{Mi} 2=41.3 ; \delta=44.7 ; \alpha=0.05)$

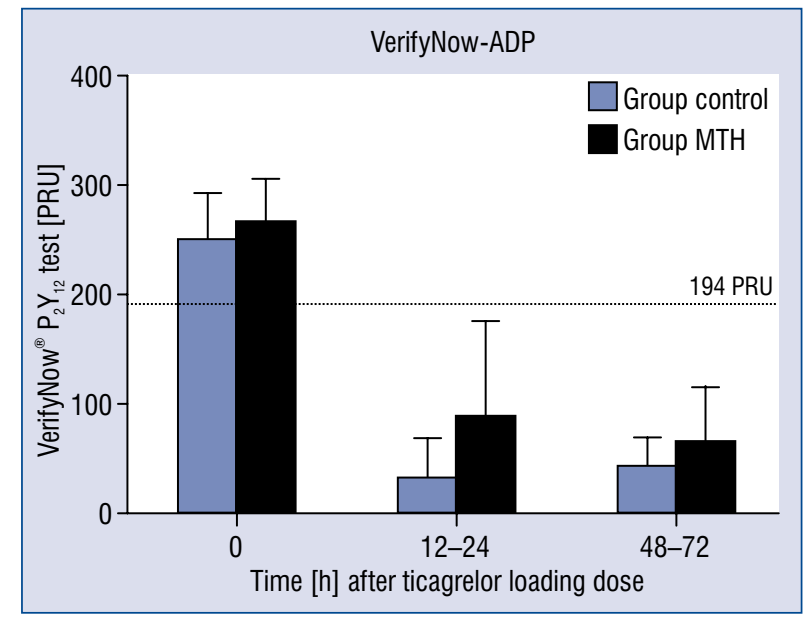

Figure 1. Data are presented as peak platelet reactivity units (PRUs) in the primary percutaneous coronary intervention-mild therapeutic hypothermia (PCI-MTH) group (black bars) and the control group (blue bars) at baseline, during hypothermia at $\mathrm{T}_{1}(12-24 \mathrm{~h})$, and after the rewarming phase at $T_{2}(48-72 \mathrm{~h})$ after the ticagrelor loading dose. Thresholds at 194 PRU indicate high on-treatment reactivity. Mean \pm standard deviation is shown. The statistical power calculations used at each time point are as follows: baseline: statistical power: 0.21 (Mi1 = 264.9; Mi2 = 246.1; $\delta=44.9 ; \alpha=0.05$ ), $\mathrm{T}_{1}$ - statistical power: $0.51(\mathrm{Mi} 1=86.7 ; \mathrm{Mi2}=31.1$; $\delta=75.63 ; \alpha=0.05), \mathrm{T}_{2}$ - statistical power: 0.27 (Mi1 = $=63.6 ; \mathrm{Mi} 2=41.3 ; \delta=44.7 ; \alpha=0.05) ; \mathrm{p}<0.05$; ADP — adenosine diphosphate.

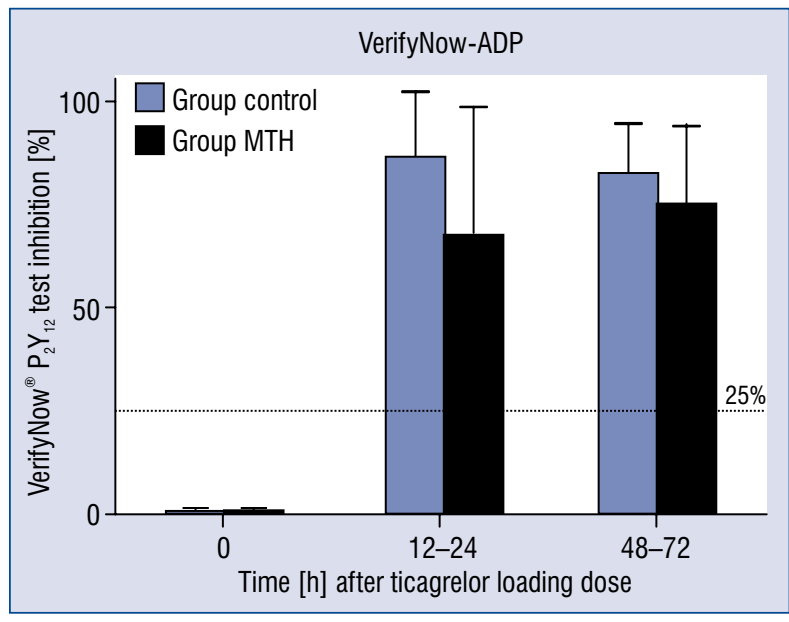

Figure 2. VerifyNow platelet reactivity in $P_{2} Y_{12}$ assay (Accumetrics, Inc., San Diego, CA, USA). Data show a comparison of the antiplatelet effect between the primary percutaneous coronary intervention-mild therapeutic hypothermia (PCI-MTH) group (black bars) and the control group (blue bars) at baseline, $\mathrm{T}_{1}(12-24 \mathrm{~h})$, and $\mathrm{T}_{2}$ (48-72 h) after a loading dose of ticagrelor. Platelet reactivity is expressed as the percentage of platelet inhibition. Mean \pm standard deviation is shown, $p<0.05$. The statistical power calculations used at each time point are as follows: baseline: statistical power: 0.05 (Mi1 $=0.22$; Mi2 $=0.35 ; \delta=1.13 ; \alpha=0.05), \mathrm{T}_{1}-$ statistical power: 0.48 (Mi1 = 67.4; Mi2 = 86.4; $\delta=26.9 ; \alpha=0.05), \mathrm{T}_{2}$ statistical power: 0.25 (Mi1 = 74.7; $\mathrm{Mi2}=82.6 ; \delta=16.6$; $\alpha=0.05) ; \mathrm{p}<0.05 ;$ ADP - adenosine diphosphate. 


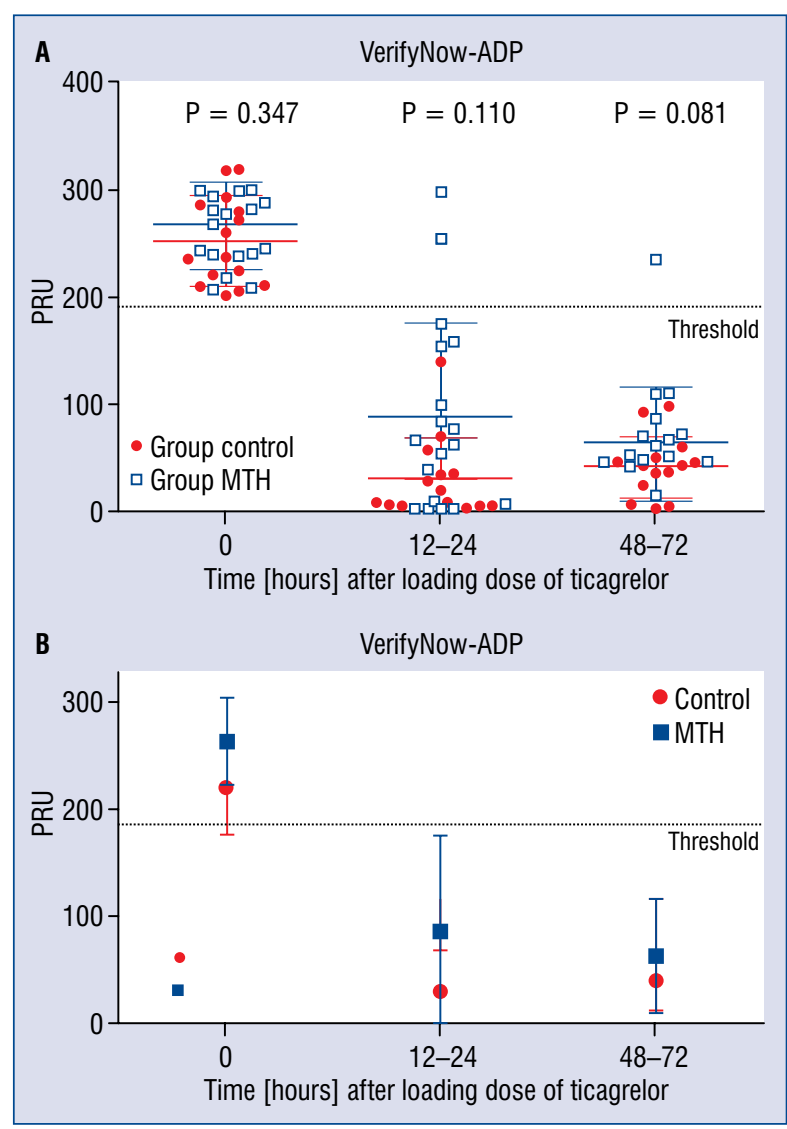

Figure 3. A. Platelet reactivity by treatment. VerifyNow $\mathrm{P}_{2} \mathrm{Y}_{12}$ assay results: Individual results for the VerifyNow $\mathrm{P}_{2} \mathrm{Y}_{12}$ assay (Accumetrics, Inc., San Diego, CA, USA) are expressed as $P_{2} Y_{12}$ reaction units (platelet reactivity units [PRU]) at baseline $(0 \mathrm{~h})$ and each measured time point: $T_{1}(12-24 h)$ and $T_{2}(48-72 h)$ after ticagrelor loading dose. Platelet inhibition with $90 \mathrm{mg}$ ticagrelor twice daily in $\mathrm{n}=18$ primary percutaneous coronary intervention-mild therapeutic hypothermia (PCl-MTH) patients (empty blue squares) is shown in comparison to $\mathrm{n}=14$ normothermic patients after primary $\mathrm{PCl}$ in the control group (red dots). Solid lines with error bars indicate the least-square means (95\% confidence interval). The dashed line indicates a level of 194 PRU as a threshold for high platelet reactivity. There is no significant difference between the groups (all $p>0.01$ ); ADP - adenosine diphosphate; B. Inhibition of platelet aggregation by VerifyNow $\mathrm{P}_{2} \mathrm{Y}_{12}$ assay (Accumetrics, Inc., San Diego, CA, USA) at baseline ( $0 \mathrm{~h}), \mathrm{T}_{1}(12-24 \mathrm{~h})$, and $\mathrm{T}_{2}(48-72 \mathrm{~h})$ after ticagrelor loading and maintenance therapy in $\mathrm{n}=18$ primary percutaneous coronary intervention-mild therapeutic hypothermia (PCI-MTH) patients (blue squares) and $n=14$ control group (red dots). Solid lines with error bars indicate the least-square means (95\% confidence interval). The dashed line indicates a level of 194 platelet reactivity units (PRU) as a threshold for high platelet reactivity; $p>0.01$; ADP — adenosine diphosphate. intestinal tract, and in 2 other cases, bleeding was related to arterial puncture site bleeding. In the last 2 cases, bleeding from the mucosa of the nostrils after insertion of a nasogastric tube and bronchial bleeding were observed.

\section{Discussion}

The main finding of the present study was that ticagrelor effectively inhibited platelet aggregation in a population of OHCA patients subjected to MTH for $24 \mathrm{~h}$ while undergoing primary PCI. The effectiveness of ticagrelor did not differ between either group, which is in line with previous reports [14, 19]. In 2 cases in the MTH population, platelet response to ticagrelor was inadequate, and in 1 of them it remained insufficient during the re-warming phase. In the first case, ticagrelor resistance may have been associated with impaired drug absorption secondary to reduced gastric and intestinal perfusion from decreased cardiac output in the course of cardiogenic shock [26]. In the second case, the resistance of platelets to ticagrelor during hypothermia which persisted in the re-warming phase may have been due to preactivation of platelets caused by a higher baseline expression of activated glycoprotein IIb/IIIa in the course of advanced diabetes in a subject dialyzed for many years. This is in line with a previous publication that explicitly addressed the impact of renal impairment on residual platelet reactivity during DAPT in VN-P $\mathrm{P}_{2} \mathrm{Y}_{12}$ assessment $[27,28]$. Of importance, according to previous pharmacodynamic and pharmacokinetic studies, ticagrelor can be safely used in patients with renal insufficiency, including those on dialysis [29].

To assess the potential impact of MTH on the antiplatelet effect of ticagrelor, we compared patients undergoing hypothermia after $\mathrm{CA}$ with the control group of patients with only MI. The degree of platelet inhibition $12-24 \mathrm{~h}$ after administration of ticagrelor in the MTH group was similar to that observed by the TICOMA investigators [18] and others, where sufficient platelet inhibition was achieved just after $3 \mathrm{~h}$ [18] and persisted during the $24-48 \mathrm{~h}$ period after the $\operatorname{LD}[18,19]$. Similar results were reported by Tileman et al. [15], who showed that the degree of platelet inhibition measured by impedance aggregometry $24 \mathrm{~h}$ after an LD of ticagrelor did not differ between 27 hypothermic and 10 normothermic patients with acute MI. Based on data from $9 \mathrm{OHCA}$ patients who underwent PCI 
and MTH and were given ticagrelor, the platelet reactivity index (PRI) value after $24 \mathrm{~h}$ was within the effective range in all cases in the assessment of PRI/vasodilator-stimulated phosphoprotein (VASP) [31]. Different observations were made by Ibrahim et al. [9], who found PRI/VASP values above $50 \%$ in $3(33.33 \%)$ out of 10 PCI-MTH patients on ticagrelor treatment. Similarly, Kander et al. [33] recognized that in $7(50 \%)$ out of 14 patients with dual-platelet inhibition, the effect of ticagrelor on platelets was still insufficient $12-24 \mathrm{~h}$ after induction of MTH and did not reach the target VASP PRI $<50$ when measured by flow cytometry-based VASP. The authors of that study hypothesized that a probable cause of this phenomenon could be delayed gastric emptying in the MTH group [9, 32].

Our results confirm that a high rate of effective blocking of the $\mathrm{P}_{2} \mathrm{Y}_{12}$ receptor by ticagrelor in the MTH group translated into a lack of ST, which is contrary to doubts raised by earlier researchers emphasizing the attenuated effect of $\mathrm{P}_{2} \mathrm{Y}_{12}$ inhibitors caused by cooling [10, 11,33]. In all patients included in our study, initiation of hypothermia was preceded by the administration of an LD of ASA and ticagrelor. The ATLANTIC trial highlights the importance of administering ticagrelor as early as possible to affect clinical endpoints [34]. In our study, we assessed platelet reactivity as a surrogate marker of thrombotic complication, because $\mathrm{VN}-\mathrm{P}_{2} \mathrm{Y}_{12}$ assessment has previously been used as a measure of platelet reactivity in response to MTH [19]. Overall, we did not observe ST or recurrent MI or unscheduled re-angiography in the MTH group. Similar results with 0\% ST in OHCA patients undergoing MTH and PCI were observed by other researchers in groups of 27 [15], 33 [35], and 45 [36] patients, which was only slightly different from the $2.5 \%$ ST reported ST among 40 patients [37]. In all of the studies except one [36], subjects received pre-treatment with a full dose of heparin, ASA, and an LD of $\mathrm{P}_{2} \mathrm{Y}_{12}$ inhibitor before cooling, which possibly minimized the risk for ST as described earlier [34]. Different results were presented in several other reports involving small groups of patients, indicating a relationship between the use of MTH and the occurrence of ST, the frequency of which varied from $10.9 \%$ to $49 \%$ $[11,33]$. In a study by Ibrahim et al. [9], $4(14.8 \%)$ patients from a group of 27 patients undergoing MTH and PCI after OHCA had ST. However, no subject from this group was given a $\mathrm{LD}$ of $\mathrm{P}_{2} \mathrm{Y}_{12}$ antagonist as pretreatment [9]. Another study of a small cohort of patients treated with OHCA in conjunction with MTH where hypothermia was maintained for 24-48 h also observed a high occurrence of ST in 5 (45.5\%) of 11 subjects. The average time from PCI to ST was $174 \mathrm{~h}$, indicating that thrombotic incidents may have been associated with causes other than MTH [33].

A second important issue regarding prevention of acute and subacute ST risk in the MTH group is related to avoiding implantation of undersized stents, which may occur as a result of underestimating the diameter of an infarct-related artery secondary to coronary vasospasm in the course of cooling [38]. In 2014 and 2015, Joffre et al. [11] as well as Gouffran et al. [10] observed a $10.9 \%$ incidence of ST in the population they researched. Both studies were conducted retrospectively without comparative groups. In the first study, $46(83.6 \%)$ out of 55 patients were in cardiogenic shock and required continuous vasopressor infusion [11]. This may have promoted coronary vasoconstriction and potentially impacted the operator's assessment of stent sizing, which may have led to length overestimation (average stent length of $26 \mathrm{~mm}$ ) and stent diameter under-sizing with suboptimal expansion that could facilitate risk of ST. Hypothermia in this group was maintained for $24 \mathrm{~h}$ with a re-warming phase up to the next $24 \mathrm{~h}$. The average delay for ST after baseline in this study was $3 \pm 1.7$ days, and in $2(3.6 \%)$ out of 55 cases ST occurred within $24 \mathrm{~h}$, while in the other $4(7.2 \%)$ cases it occurred on the third day or later. Importantly, only $53 \%$ of OHCA patients in this study were pre-treated with ASA and $51 \%$ were pre-treated with heparin before stent implantation, and none of them had received DAPT [11]. In the second study [10], MTH with the re-warming phase was maintained for 24-36 h. The median time from PCI to ST was 2 days (mean time: $2.5 \pm 2.3$ days). Angiographically-confirmed ST during the first $48 \mathrm{~h}$ occurred in only $5(4.9 \%)$ cases, while the remaining $3(2.9 \%)$ were recognized only based on clinical suspicion [10] and, according to the BARC definition of ST [23], could be qualified only as a "possible event". A meta-analysis of 5 clinical trials involving a total of 290 patients who underwent PCI treatment with MTH showed an incidence of ST of $6 \%$, which was higher than reported in non-hypothermia conditions. Importantly, the study mentioned above did not confirm significant differences between the frequency of ST between the groups treated with clopidogrel and those receiving newer agents (ticagrelor or prasugrel) [39].

The most compelling evidence regarding the relationship between the use of MTH and the risk of ST comes from a multicenter analysis by 
Shah et al. [16], which included 49,109 patients who underwent a primary PCI, of whom 1,193 underwent MTH. There was no difference in ST incidence between the MTH and non-MTH groups (3.9\% vs. $4.7 \%)$, which was further confirmed by propensity-matched analysis [16]. Furthermore, a meta-analysis of 9 trials including 744 patients with acute MI, who underwent PCI and were randomly assigned to either hypothermia or control treatment with target vessel revascularization, found no significant difference in the occurrence of ST between groups: ST incidence was $2.4 \%$ vs. $0.2 \%$, respectively, with a relative risk of 3.55 [0.80; 15.87] ( $\mathrm{p}=0.09)$ [39].

The occurrence of serious bleeding (BARC 3a, $3 \mathrm{~b}$ ) in our study was limited to the group of MTH patients with a frequency of 6 (33\%) patients, which is similar to reports from some previous studies $[12,40]$ and slightly more than others $[15,16]$. Given the small cohort we examined, it is possible that our observations could be accidental. In previous reports, bleeding complications were more often observed in hypothermia-treated patients only in smaller studies $[40,41]$ similar to ours, as opposed to observations of larger populations $[16,42,43]$. One potential mechanism behind the increased risk of bleeding in MTH-treated patients could be a decreased platelet count in blood serum persisting after re-warming. This is consistent with prior studies involving cooling patients [44] as well as coagulation disorders and most likely results from impaired production of clotting enzymes at temperatures below $32^{\circ} \mathrm{C}$, which was previously studied by our group and others $[7,8]$.

\section{Limitations of the study}

There are several limitations in our study. VN- $\mathrm{P}_{2} \mathrm{Y}_{12}$ is a well-established and reliable method for evaluating response to $\mathrm{P}_{2} \mathrm{Y}_{12}$ inhibitors. However, verification of our results by another test could be an added value, especially because there is no validation of the different testing systems in hypothermic patients. Unfortunately, in our study, we did not carry out serial tests of platelet function, which prevents us from determining the minimum time required to achieve effective platelet inhibition after administration of an LD of ticagrelor. We also lack sufficient data to evaluate both the early pharmacokinetic and pharmacodynamic effects of ticagrelor administered through a nasogastric tube. The lack of a control group consisting of patients after CA resulted from difficulties in recruiting such patients due to ethical reasons. Our study was conducted in 1 center, and its limited sample size had sufficient power to assess the effectiveness of platelet aggregation inhibition by ticagrelor but does not provide adequate statistical power to assess clinical endpoints.

\section{Conclusions}

The present study confirms the findings of the effectiveness of blocking platelets by ticagrelor in MI patients after OHCA treated with primary PCI undergoing hypothermia. The use of cooling was not associated with an increased risk of ST in patients in this very high-risk group, although it may be associated with a slightly increased risk of bleeding.

\section{Conflict of interest: None declared}

\section{References}

1. Berdowski J, Berg RA, Tijssen JGP, et al. Global incidences of out-of-hospital cardiac arrest and survival rates: Systematic review of 67 prospective studies. Resuscitation. 2010; 81(11): 1479-1487, doi: 10.1016/j.resuscitation.2010.08.006, indexed in Pubmed: 20828914.

2. Dumas F, Cariou A, Manzo-Silberman S, et al. Immediate percutaneous coronary intervention is associated with better survival after out-of-hospital cardiac arrest: insights from the PROCAT (Parisian Region Out of hospital Cardiac ArresT) registry. Circ Cardiovasc Interv. 2010; 3(3): 200-207, doi: 10.1161/CIRCINTERVENTIONS.109.913665, indexed in Pubmed: 20484098.

3. Hypothermia after Cardiac Arrest Study Group. Mild therapeutic hypothermia to improve the neurologic outcome after cardiac arrest. N Engl J Med. 2002; 346(8): 549-556, doi: 10.1056/NEJMoa012689, indexed in Pubmed: 11856793.

4. Erecinska M, Thoresen M, Silver IA. Effects of hypothermia on energy metabolism in Mammalian central nervous system. J Cereb Blood Flow Metab. 2003; 23(5): 513-530, doi: 10.1097/01. WCB.0000066287.21705.21, indexed in Pubmed: 12771566.

5. Kern KB, Lotun K, Patel N, et al. Outcomes of comatose cardiac arrest survivors with and without st-segment elevation myocardial infarction: importance of coronary angiography. JACC Cardiovasc Interv. 2015; 8(8): 1031-1040, doi: 10.1016/j. jcin.2015.02.021, indexed in Pubmed: 26117462.

6. Kander T, Schött U. Effect of hypothermia on haemostasis and bleeding risk: a narrative review. J Int Med Res. 2019; 47(8): 3559-3568, doi: 10.1177/0300060519861469, indexed in Pubmed: 31475619 .

7. Trąbka-Zawicki A, Tomala M, Zeliaś A, et al. Adaptation of global hemostasis to therapeutic hypothermia in patients with out-ofhospital cardiac arrest: Thromboelastography study. Cardiol J. 2019; 26(1): 77-86, doi: 10.5603/CJ.a2017.0080, indexed in Pubmed: 28695976.

8. Högberg C, Erlinge D, Braun OO. Mild hypothermia does not attenuate platelet aggregation and may even increase ADP-stimulated platelet aggregation after clopidogrel treatment. Thromb J. 2009; 7: 2, doi: 10.1186/1477-9560-7-2, indexed in Pubmed: 19236702. 
9. Ibrahim K, Christoph M, Schmeinck S, et al. High rates of prasugrel and ticagrelor non-responder in patients treated with therapeutic hypothermia after cardiac arrest. Resuscitation. 2014; 85(5): 649-656, doi: 10.1016/j.resuscitation.2014.02.004, indexed in Pubmed: 24555950.

10. Gouffran G, Rosencher J, Bougouin W, et al. Stent thrombosis after primary percutaneous coronary intervention in comatose survivors of out-of-hospital cardiac arrest: Are the new P2Y12 inhibitors really more effective than clopidogrel? Resuscitation. 2016; 98: 73-78, doi: 10.1016/j.resuscitation.2015.11.006, indexed in Pubmed: 26610376.

11. Joffre J, Varenne O, Bougouin W, et al. Stent thrombosis: an increased adverse event after angioplasty following resuscitated cardiac arrest. Resuscitation. 2014; 85(6): 769-773, doi: 10.1016/j.resuscitation.2014.02.013, indexed in Pubmed: 24572484.

12. Jiménez-Britez G, Freixa X, Flores-Umanzor E, et al. Out-ofhospital cardiac arrest and stent thrombosis: Ticagrelor versus clopidogrel in patients with primary percutaneous coronary intervention under mild therapeutic hypothermia. Resuscitation. 2017; 114: 141-145, doi: 10.1016/j.resuscitation.2017.02.015, indexed in Pubmed: 28242212.

13. Chisholm GE, Grejs A, Thim T, et al. Safety of therapeutic hypothermia combined with primary percutaneous coronary intervention after out-of-hospital cardiac arrest. Eur Heart J Acute Cardiovasc Care. 2015; 4(1): 60-63, doi: 10.1177/2048872614540093, indexed in Pubmed: 24944239.

14. Moudgil R, Al-Turbak H, Osborne C, et al. Superiority of ticagrelor over clopidogrel in patients after cardiac arrest undergoing therapeutic hypothermia. Can J Cardiol. 2014; 30(11): 1396-1399, doi: 10.1016/j.cjca.2014.07.745, indexed in Pubmed: 25442437.

15. Tilemann LM, Stiepak J, Zelniker T, et al. Efficacy of enteral ticagrelor in hypothermic patients after out-of-hospital cardiac arrest. Clin Res Cardiol. 2016; 105(4): 332-340, doi: 10.1007/ s00392-015-0925-1, indexed in Pubmed: 26508414.

16. Shah N, Chaudhary R, Mehta K, et al. Therapeutic Hypothermia and Stent Thrombosis: A Nationwide Analysis. JACC Cardiovasc Interv. 2016; 9(17): 1801-1811, doi: 10.1016/j.jcin.2016.06.052, indexed in Pubmed: 27609254.

17. Eyileten C, Soplinska A, Pordzik J, et al. Effectiveness of antiplatelet drugs under therapeutic hypothermia: a comprehensive review. Clin Pharmacol Ther. 2019; 106(5): 993-1005, doi: 10.1002/cpt.1492, indexed in Pubmed: 31055838.

18. Ratcovich H, Sadjadieh G, Andersson HB, et al. The effect of TIcagrelor administered through a nasogastric tube to COMAtose patients undergoing acute percutaneous coronary intervention: the TICOMA study. EuroIntervention. 2017; 12(14): 1782-1788, doi: 10.4244/EIJ-D-16-00398, indexed in Pubmed: 28216475 .

19. Steblovnik K, Blinc A, Mijovski MB, et al. Ticagrelor versus clopidogrel in comatose survivors of out-of-hospital cardiac arrest undergoing percutaneous coronary intervention and hypothermia: a randomized study. Circulation. 2016; 134(25): 2128-2130, doi: 10.1161/CIRCULATIONAHA.116.024872, indexed in Pubmed: 27994027.

20. Chyrchel B, Drożdż A, Długosz D, et al. Platelet reactivity and circulating platelet-derived microvesicles are differently affected by P2Y receptor antagonists. Int J Med Sci. 2019; 16(2): 264-275, doi: 10.7150/ijms.28580, indexed in Pubmed: 30745807.
21. Marcucci CE, Schoettker P. editors. Perioperative Hemostasis: Coagulation for Anesthesiologists. Heidelberg: Springer Berlin Heidelberg, Berlin 2015.

22. Accumetrics. VerifyNow. User Manual Company Technical Booklet. 2009;138.

23. Cutlip DE, Windecker S, Mehran R, et al. Academic Research Consortium. Clinical end points in coronary stent trials: a case for standardized definitions. Circulation. 2007; 115(17): 2344-2351, doi: 10.1161/CIRCULATIONAHA.106.685313, indexed in Pubmed: 17470709.

24. Mehran R, Rao SV, Bhatt DL, et al. Standardized bleeding definitions for cardiovascular clinical trials: a consensus report from the Bleeding Academic Research Consortium. Circulation. 2011; 123(23): 2736-2747, doi: 10.1161/CIRCULATIONAHA.110.009449, indexed in Pubmed: 21670242.

25. Aradi D, Storey RF, Komócsi A, et al. Expert position paper on the role of platelet function testing in patients undergoing percutaneous coronary intervention. Eur Heart J. 2014; 35(4): 209-215, doi: 10.1093/eurhearti/eht375, indexed in Pubmed: 24067509.

26. Zeymer U, Bueno H, Granger CB, et al. Acute Cardiovascular Care Association position statement for the diagnosis and treatment of patients with acute myocardial infarction complicated by cardiogenic shock: A document of the Acute Cardiovascular Care Association of the European Society of Cardiology. Eur Heart J Acute Cardiovasc Care. 2020; 9(2): 183-197, doi: 10.1177/2048872619894254, indexed in Pubmed: 32114774.

27. Alexopoulos D, Xanthopoulou I, Plakomyti TE, et al. Ticagrelor in clopidogrel-resistant patients undergoing maintenance hemodialysis. Am J Kidney Dis. 2012; 60(2): 332-333, doi: 10.1053/j. ajkd.2012.05.001, indexed in Pubmed: 22658575.

28. Gremmel T, Müller M, Steiner S, et al. Chronic kidney disease is associated with increased platelet activation and poor response to antiplatelet therapy. Nephrol Dial Transplant. 2013; 28(8): 2116-2122, doi: 10.1093/ndt/gft103, indexed in Pubmed: 23729489.

29. Jeong KH, Cho JuH, Woo JS, et al. Platelet reactivity after receiving clopidogrel compared with ticagrelor in patients with kidney failure treated with hemodialysis: a randomized crossover study. Am J Kidney Dis. 2015; 65(6): 916-924, doi: 10.1053/j. ajkd.2014.11.023, indexed in Pubmed: 25622774.

30. Alexopoulos D, Xanthopoulou I, Gkizas V, et al. Randomized assessment of ticagrelor versus prasugrel antiplatelet effects in patients with ST-segment-elevation myocardial infarction. Circ Cardiovasc Interv. 2012; 5(6): 797-804, doi: 10.1161/CIRCINTERVENTIONS.112.972323, indexed in Pubmed: 23169985.

31. Bednar F, Kroupa J, Ondrakova M, et al. Antiplatelet efficacy of P2Y12 inhibitors (prasugrel, ticagrelor, clopidogrel) in patients treated with mild therapeutic hypothermia after cardiac arrest due to acute myocardial infarction. J Thromb Thrombolysis. 2016; 41(4): 549-555, doi: 10.1007/s11239-015-1274-7, indexed in Pubmed: 26340851.

32. Kander T, Dankiewicz J, Friberg H, et al. Platelet aggregation and clot formation in comatose survivors of cardiac arrest treated with induced hypothermia and dual platelet inhibition with aspirin and ticagrelor; a prospective observational study. Crit Care. 2014; 18(5): 495, doi: 10.1186/s13054-014-0495-z, indexed in Pubmed: 25292183.

33. Penela D, Magaldi M, Fontanals J, et al. Hypothermia in Acute Coronary Syndrome. J Am Coll Cardiol. 2013; 61(6): 686-687, doi: 10.1016/j.jacc.2012.10.029. 


\section{Cardiology Journal}

34. Montalescot G, van ,t Hof AW, Montalescot G, et al. Prehospital ticagrelor in ST-segment elevation myocardial infarction. N Engl J Med. 2014; 371(11): 1016-1027, doi: 10.1056/NEJMoa1407024, indexed in Pubmed: 25175921.

35. Kozinski M, Pstragowski K, Kubica JM, et al. ACS networkbased implementation of therapeutic hypothermia for the treatment of comatose out-of-hospital cardiac arrest survivors improves clinical outcomes: the first European experience. Scand J Trauma Resusc Emerg Med. 2013; 21: 22, doi: 10.1186/17577241-21-22, indexed in Pubmed: 23531402.

36. Casella G, Carinci V, Cavallo P, et al. Combining therapeutic hypothermia and emergent coronary angiography in out-of-hospital cardiac arrest survivors: Optimal post-arrest care for the best patient. Eur Heart J Acute Cardiovasc Care. 2015; 4(6): 579-588, doi: 10.1177/2048872614564080, indexed in Pubmed: 25522746.

37. Knafelj R, Radsel P, Ploj T, et al. Primary percutaneous coronary intervention and mild induced hypothermia in comatose survivors of ventricular fibrillation with ST-elevation acute myocardial infarction. Resuscitation. 2007; 74(2): 227-234, doi: 10.1016/j. resuscitation.2007.01.016, indexed in Pubmed: 17383070.

38. Akin I, Rehders TC, Kische S, et al. Diffuse coronary spasm during therapeutic hypothermia. Int J Cardiol. 2011; 148(3): 373-375, doi: 10.1016/j.ijcard.2010.10.065, indexed in Pubmed: 21126781.

39. Alushi B, Ndrepepa G, Lauten A, et al. Hypothermia in patients with acute myocardial infarction: a meta-analysis of randomized trials. Clin Res Cardiol. 2021; 110(1): 84-92, doi: 10.1007/ s00392-020-01652-7, indexed in Pubmed: 32303830.

40. Wolfrum S, Pierau C, Radke PW, et al. Mild therapeutic hypothermia in patients after out-of-hospital cardiac arrest due to acute ST-segment elevation myocardial infarction undergoing immediate percutaneous coronary intervention. Crit Care Med. 2008; 36(6): 1780-1786, doi: 10.1097/CCM.0b013e31817437ca, indexed in Pubmed: 18496378.

41. Zimmermann S, Flachskampf FA, Schneider R, et al. Mild therapeutic hypothermia after out-of-hospital cardiac arrest complicating ST-elevation myocardial infarction: long-term results in clinical practice. Clin Cardiol. 2013; 36(7): 414-421, doi: 10.1002/ clc.22131, indexed in Pubmed: 23649889.

42. Wang $\mathrm{CH}$, Chen NC, Tsai MS, et al. Therapeutic hypothermia and the risk of hemorrhage: a systematic review and meta-analysis of randomized controlled trials. Medicine (Baltimore). 2015; 94(47): e2152, doi: 10.1097/MD.0000000000002152, indexed in Pubmed: 26632746.

43. Nielsen N, Wetterslev J, Cronberg T, et al. Targeted temperature management at $33^{\circ} \mathrm{C}$ versus $36^{\circ} \mathrm{C}$ after cardiac arrest. N Engl J Med. 2013; 369(23): 2197-2206, doi: 10.1056/nejmoa1310519.

44. Polderman KH, Herold I. Therapeutic hypothermia and controlled normothermia in the intensive care unit: practical considerations, side effects, and cooling methods. Crit Care Med. 2009; 37(3): 1101-1120, doi: 10.1097/CCM.0b013e3181962ad5, indexed in Pubmed: 19237924. 